Natural Hazards and Earth System Sciences (2003) 3: 703-712

(C) European Geosciences Union 2003

Natural Hazards and Earth System Sciences

\title{
Strong earthquakes can be predicted: a multidisciplinary method for strong earthquake prediction
}

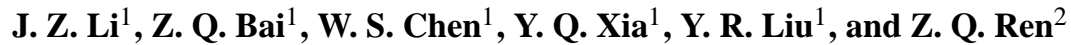 \\ ${ }^{1}$ Institute of Earthquake Prediction Research, Beijing University of Technology, Beijing 100022, P. R. China \\ ${ }^{2}$ Chinese Academy of Meteorological Sciences, No. 46 Zhongguancun South Road, Beijing 100081, P. R. China
}

Received: 17 July 2002 - Revised: 19 April 2003 - Accepted: 22 May 2003

\begin{abstract}
The imminent prediction on a group of strong earthquakes that occurred in Xinjiang, China in April 1997 is introduced in detail. The prediction was made on the basis of comprehensive analyses on the results obtained by multiple innovative methods including measurements of crustal stress, observation of infrasonic wave in an ultra low frequency range, and recording of abnormal behavior of certain animals. Other successful examples of prediction are also enumerated. The statistics shows that above $40 \%$ of 20 total predictions jointly presented by J. Z. Li, Z. Q. Ren and others since 1995 can be regarded as effective. With the above methods, precursors of almost every strong earthquake around the world that occurred in recent years were recorded in our laboratory. However, the physical mechanisms of the observed precursors are yet impossible to explain at this stage.
\end{abstract}

\section{Introduction}

Geller et al. (1997) postulated that no short-term or imminent earthquake predictions could be made. The general public is anxious to see that scientists learn to make imminent predictions just a few days before an earthquake really happens. A high level of preparedness can then be implemented to reduce deaths, injuries and other losses. Imminent prediction is one of the most difficult earthquake predictions and still remains a universal scientific problem. We have adopted innovative multiple methods in the research on the possible precursors of earthquakes to find their causal relationships with earthquakes and to make imminent predictions ( $\mathrm{Li}$ et al., 1990). Here we report some of our recent results.

Correspondence to: J. Z. Li (bpuquake@ 163bj.com)

\section{An example of successful imminent earthquake prediction}

\subsection{The prediction process of the Xinjiang earthquakes}

In April 1997, several strong earthquakes occurred in Jiashi, Xinjiang Autonomous Region, China (Fig. 1). We accurately predicted the onset just three days before the events ( $\mathrm{Li}$ et al., 1998). This imminent prediction was very effective in preparing for a natural calamity; in 11 days there were four strong earthquakes with $M_{s}$ above 6 , yet only nine people died in this area with a population of 300000 .

a) At 17:00, 3 April 1997, we completed and jointly signed the "Short and Imminent Prediction Card" which was sent to the Center of Analysis and Prediction in China Seismological Bureau (CSB) by special urgent document delivery. The prediction said that there would be an $M_{s} 7.0 \sim 7.5$ earthquake in the region of Jiashi, Xinjiang Autonomous Region, China during 4 to 10 April (see Table 1).

b) At 20:00, 3 April 1997, Mr. D. L. Zheng, from the Center of Analysis and Prediction in CSB called us to enquire on what basis we had made the report. We explained in detail to him about our methods of crustal stress, infrasonic wave, abnormal behavior of certain animals and superposition of tide generating force resonance. We requested him to transfer our prediction to the local seismological bureau of Xinjiang. He followed our suggestion to notify them by phone that evening and send a fax of our prediction card on the next day.

c) In the morning of 6 April, two earthquakes with magnitude of $M_{s} 6.3$ and $M_{s} 6.4$ occurred in the area we predicted. Mr. G. M. Zhang, the deputy director of the Center of Earthquake Analysis and Prediction in CSB called us to express thanks and congratulations for our successful prediction. We told him that, according to the abnormal amplitude of $1250 \mathrm{mV}$ of the infrasonic wave we detected, the magnitude of the earthquake should be over $M_{s} 7$. In reality the earthquakes measuring $M_{s} 6.3$ and $M_{s} 6.4$, respectively, were not as strong as we predicted. In our opinion, the energy had not yet been released completely. We asked Mr. Zhang 


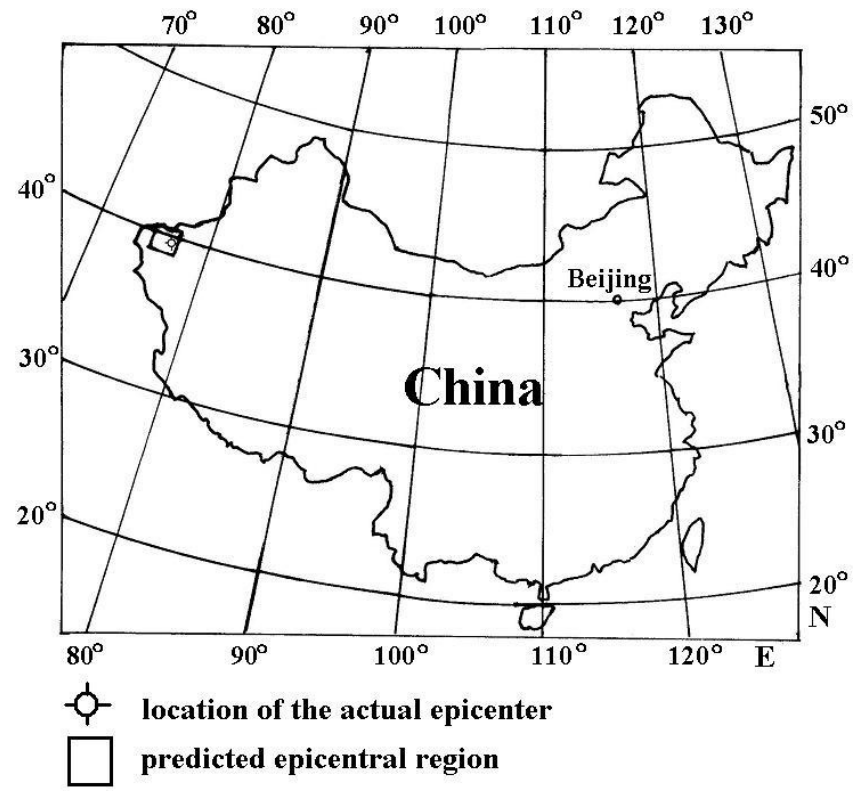

Fig. 1. Map of the location of the epicenter, Jiashi, Xinjiang Autonomous Region, China and the predicted epicentral area, actual epicenters and our Observatory.

to communicate our suggestion to the local seismological bureau of Xinjiang that there still existed the possibility of the occurrence of stronger earthquakes.

At 13:34 on 11 April another $M_{S} 6.6$ earthquake occurred in the same region and resulted in 9 fatalities.

\subsection{The accuracy of the prediction}

Table 1 is the comparison of the predicted and actual earthquakes. The precision of the level as described below has seldom been achieved, either in China or abroad. The Center of Analysis and Prediction in CSB presented us later with a success certification of our prediction.

\subsubsection{Occurring time}

The earthquake was predicted to occur within the seven days during 4 to 10 April. Within the predicted time, two earthquakes occurred at levels of $M_{s} 6.3$ and $M_{s}$ 6.4. The third earthquake of $M_{s} 6.6$ occurred at 13:34 on 11 April, which was out of the predicted time window but only by one day. The occurrences of four events with $M_{s}$ above 6 rather than one earthquake over $M_{s} 7$ might have resulted in a small prolongation of occurring time.

\subsubsection{Magnitude}

The energy released by these four events was equivalent to that of an event with $M_{s}$ 6.8. The error of the prediction on magnitude was therefore 0.2 .

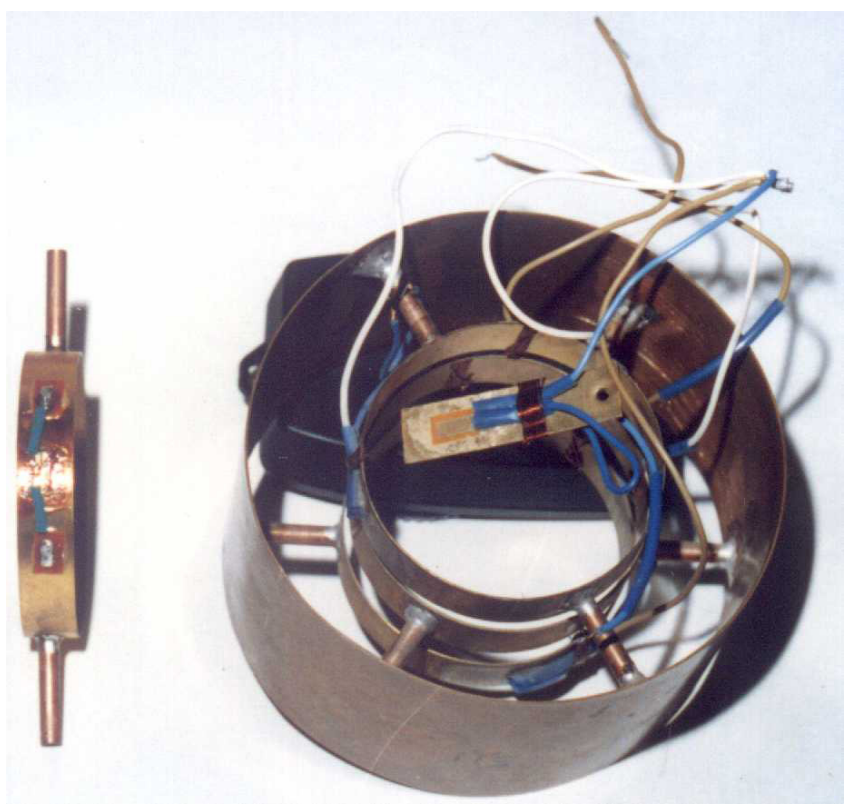

Fig. 2. Structure of the GD crustal stress transducer.

\subsubsection{Location of the epicenter}

In our system, the prediction of the epicenter location is the most difficult item of the three elements (occurring time, magnitude and epicenter location). The range of our predicted location is within latitude 1.5 degrees and longitude 2 degrees. The epicenters of the four main earthquakes were within the area.

\subsection{The basis of the prediction}

\subsubsection{Abrupt change of crustal stress}

The measurement of crustal stress is one of the basic methods for monitoring the precursor of earthquakes. We invented a crustal stress transducer called GD (the Chinese phonetic alphabetic initial letters of Beijing Polytechnic University), a crustal stress transducer with a unique structure, as shown in Fig. 2 (Li et al., 1994). The transducer consists of one large ring and three smaller rings. All the rings are made of elastic phosphor bronze sheet with a thickness of $0.3-0.5 \mathrm{~mm}$. The three smaller rings are put into the larger one and the centers of four rings are aligned in one vertical line. Two small phosphor bronze rods outside each of the smaller internal rings in the direction of the horizontal diameter connect it with the outside larger ring. Three pairs of the small rods point to different directions, north - south (component I), south by east, i.e. $\mathrm{S} 45^{\circ} \mathrm{E}$ (component II) and west - east (component III). The high sensitive electric-resistance gauges are stuck to the outer side of the smaller internal rings in the vertical direction. The crustal stress is obtained by measurement of crustal strain that the electric-resistance gauges present. In Fig. 2, on the left is a side view of a smaller ring with a pair of rods and an electric-resistance gauge stuck on it. 
Table 1. Verification of the imminent earthquake prediction of the group of strong earthquakes that occurred in Jiashi, Xinjiang Autonomous Region, China, April 1997

\begin{tabular}{|c|c|c|c|}
\hline & Prediction & Actual & Error \\
\hline Time & 7 April $1997 \pm 3$ d & $\begin{array}{l}6 \text { April } 1997 \\
6 \text { April } 1997 \\
11 \text { April } 1997\end{array}$ & $\begin{array}{c}\text { No error } \\
\text { No error } \\
13 \mathrm{~h}\end{array}$ \\
\hline Magnitude & $M_{s}=7.0 \sim 7.5$ & $M_{s}=6.3 ; M_{s}=6.4 ; M_{s}=6.6$ & 0.2 \\
\hline Place & $\begin{array}{cc}38.7^{\circ} \sim 40.2^{\circ} \mathrm{N} \\
\text { China } \quad\end{array}$ & $\begin{array}{l}39.5^{\circ} \mathrm{N}, 76.8^{\circ} \mathrm{E} \\
39.6^{\circ} \mathrm{N}, 76.9^{\circ} \mathrm{E} \\
39.7^{\circ} \mathrm{N}, 76.8^{\circ} \mathrm{E}\end{array}$ & No error \\
\hline
\end{tabular}

The transducer was inserted in a plastic bottle and was mounted firmly in it, in order to be protected from the humidity. The leads of the electric-resistance gauge come out from the opening of the bottle, which was rigidly sealed by a cap (Fig. 3). The bottle was buried in a hole of 6-7 $\mathrm{m}$ in depth in an upright position, and the hole was filled up with sand, in order to secure a uniform stress environment to the transducer.

With the crustal strains of three directions in a horizontal plane in the Earth, represented by the three smaller rings of the transducer, we can determine the direction and magnitude of the principal strain in this horizontal plane. So, the principal stress can be calculated (crustal stress $=$ crustal strain $\times$ elastic modulus), and as we know, the direction of the principal crustal stress is pointed toward the location of the epicenter (Wang et al., 1979). The formulas for the principal stress of the GD transducer were derived, and the sensitivity of the instrument is $1 \times 10^{-6} \epsilon$ ( $\mathrm{Li}$ et al., 1994). The relative value of the crustal stress instead of the absolute value is adopted for the earthquake forecasts, because the relative change in the crustal stress reflects the seismic activity. So, it is not necessary to identify the absolute stress.

With the above system, we often observed an abrupt change in crustal stress before the occurrences of the strong earthquakes, such as the $M_{s} 6.9$ event which occurred in Xinjiang $\left(40.0^{\circ} \mathrm{N}, 76.7^{\circ} \mathrm{E}\right)$ on 19 March 1996 , the $M_{s} 7.2$ event occurred in Kobe, Japan on 17 January 1995, and other Japanese earthquakes of $M_{s} 7.8$ on 28 December 1994, $M_{s} 7.9$ on 4 October $1994, M_{s} 7.0$ on 22 July $1994, M_{s} 7.7$ on 12 July 1993, and so on (Li et al., 1995). Of course, the observed crustal stress should depend on the geological structure of the region containing the location of the epicenter and the transducer, so that not all the strong earthquakes around the world can generate an observable anomaly in crustal stress before their occurrences.

The abrupt change in the crustal stress called our attention to the Xinjiang earthquakes. The reason was as follows. On 13 to 15 March 1996, there was a sudden change in component I of the GD crustal stress transducer, buried at

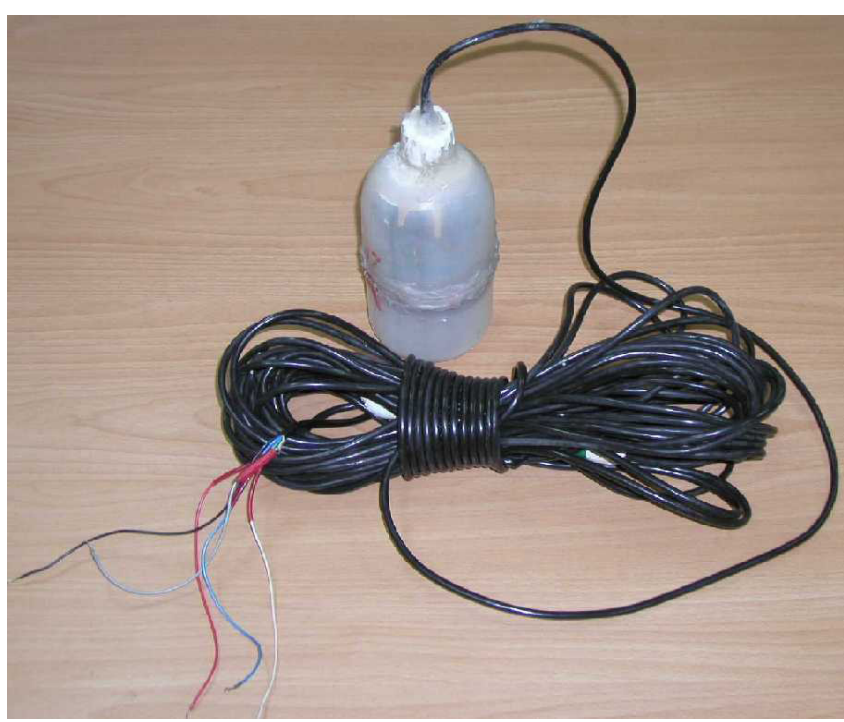

Fig. 3. Sealed GD crustal stress transducer and the cable.

$7 \mathrm{~m}$ depth in the south area of Beijing. The rate of the sudden change was $2.2 \mathrm{~N} / \mathrm{cm}^{2}$, and after the appearance of this signal, an $M_{s} 6.9$ earthquake occurred in Artushi, Xinjiang (Fig. 4). Considering the long distance between Beijing and Xinjiang ( $>3000 \mathrm{~km})$, this sequence of events was hard to explain in terms of physics. They could have been mere coincidences. However, again, during 26 to 30 March 1997, we detected an abrupt change in the same component I of the same GD crustal stress transducer at the rate of $3.7 \mathrm{~N} / \mathrm{cm}^{2}$ (Fig. 5). Based on the past measurements mentioned above, we suspected that the sudden change in March 1997 could have been the short and imminent precursor information of a strong earthquake in Xinjiang. Whether this judgment was correct or not, was not certain, but the sudden change did attract our attention to the possibility of a strong earthquake in Xinjiang. Figure 6 is the record of crustal stress during January 1996 to June 1997. 


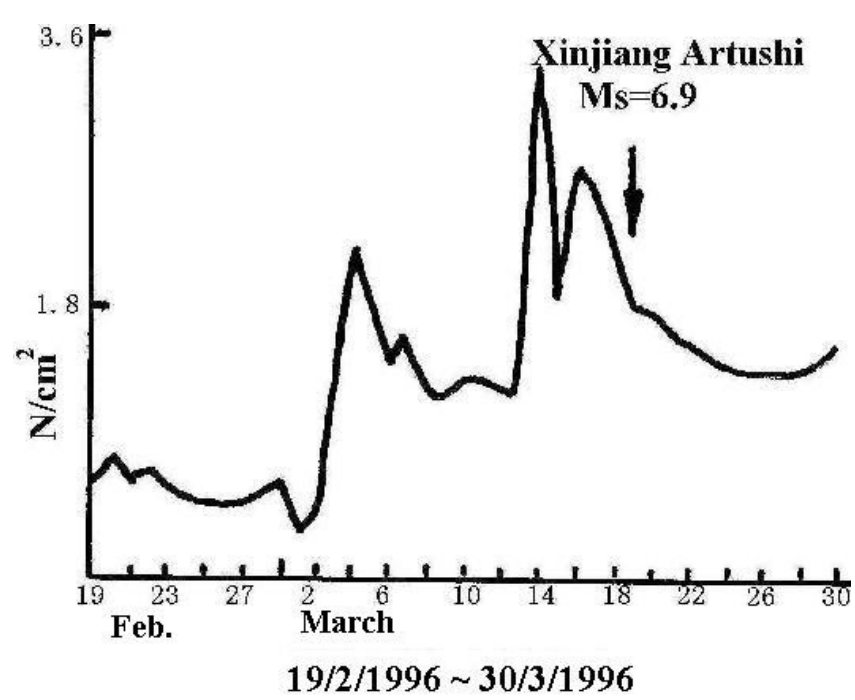

Fig. 4. Abnormal curve of GD6\# (I) crustal stress during 19 February 1996 to 30 March 1996 (the mean value for every day).

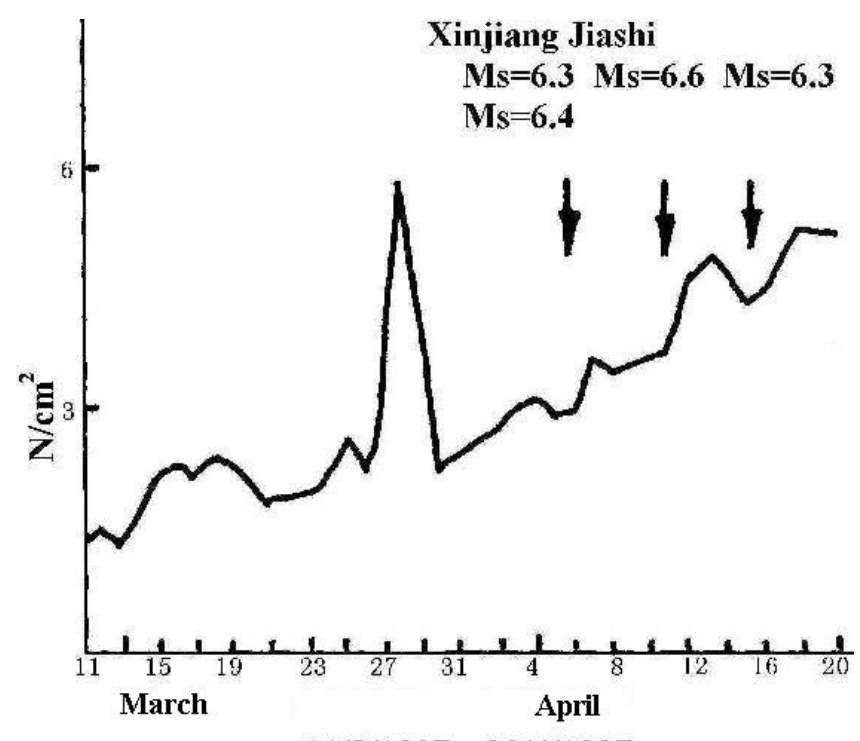

11/3/1997 20/4/1997

Fig. 5. Abnormal curve of GD6\# (I) crustal stress during $11 / 03 / 1997$ to $20 / 04 / 1997$ (the mean value for every day).

\subsubsection{Abnormal infrasonic wave signals}

The second indicator came from abnormal signals of infrasonic sound waves. The advantage of infrasonic sound waves with the ultra low frequency is that they can propagate long distances because of very low attenuation (McDonald, 1971). The observation of infrasonic sound waves is an important method to recognize an imminent precursor in our laboratory.

The infrasonic wave that we measured is considered to have been released from a fault fracture at the epicenter. The theory of infrasonic wave observation is based on the tests of rock destruction. In 1982, we made 35 tests with various kinds of rocks and with the same transducer adopted for

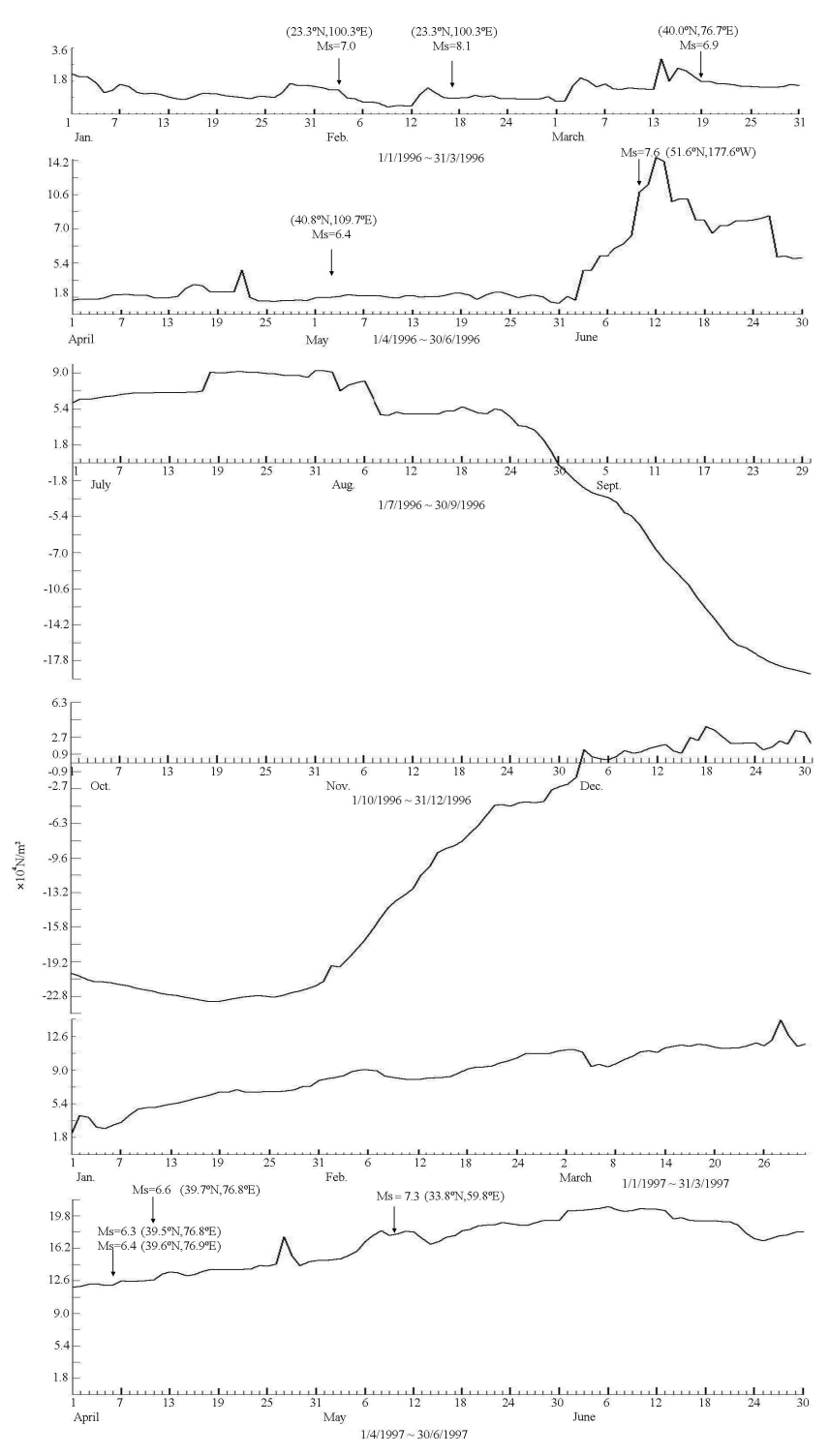

Fig. 6. Abnormal curve of GD6\# (I) crustal stress during 01 January 1996 to 30 June 1997 (the mean value for every day).

monitoring the precursor of an earthquake afterward. The conclusion of our experiments is that infrasonic waves are released before the main fracture of the rocks (Li et al., 1982).

Actually, in nature the frequency of the pre-seismic sound wave is much lower than our experimental ones. We set up an infrasonic wave observation system by choosing an infrasonic sound sensor with a frequency from 0.004 to $0.1 \mathrm{~Hz}$. The sensor is a kind of infrasound condenser microphone developed by the Institute of Acoustics in Chinese Academy of Science. The pressure-sensitive element of the sensor is a membrane or a diaphragm. A recorder draws the change of pressure-sensitive element, i.e. displacement or velocity; that is an infrasonic signal.

The appearance and general structure of the infrasound condenser microphone is shown in Fig. 7. The detailed structure map (Fig. 8) shows its atmospheric inlet, front cavity, 

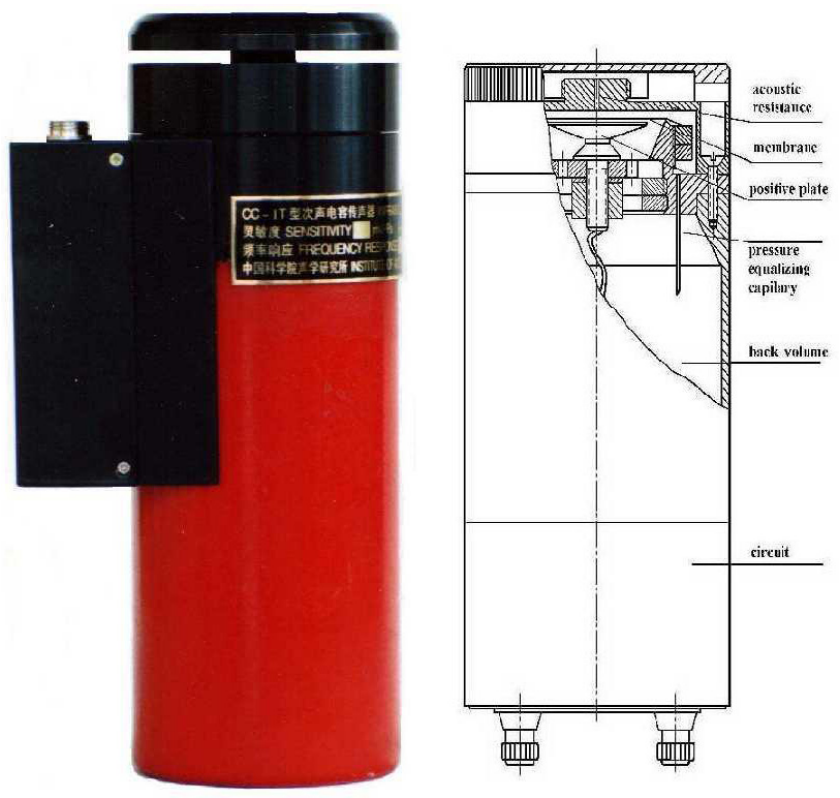

Fig. 7. Appearance and sketch for the configuration of condenser type infrasonic microphone.

membrane, atmospheric pressure equalizing capillary and back cavity. The equivalent circuit was shown in Fig. 9. $P$ represents atmospheric pressure signals, $Q$ represents volume shift of membrane. The front cavity inlet allows for the sound pressure signals to enter the microphone. The acoustic resistance $R_{1}$ and compliance $C_{1}$ of the front cavity compose a low-pass filter, which determines the high cutoff frequency. The pressure-equalizing capillary connects the front and back cavities. When the volume of the back cavity and the tension of the membrane are fixed, the low frequency characteristic is determined by $R_{2}$, the acoustic resistance of the pressure-equalizing capillary.

To measure the slow change in the capacitance value, a process including amplitude modulation, amplification and demodulation is used to convert a high frequency signal to a low frequency signal. Its operational principle was shown in Fig. 10. Figure 11 is a circuit of bridge amplitude modulation adopted in the above process, in which $M$ is an infrasound transducer, $U_{i}$ is a high frequency signal source, $U_{0}$ is the output voltage and $C_{0}$ is the head capacitance of the transducer. $\Delta C$ is the changed value of the capacitance caused by pressure signals. The relationship among them is

$U_{0}=\frac{U_{i}}{2} \frac{\Delta C / C_{0}}{2+\left(\Delta C / C_{0}\right)}$.

Here, the relation between $U_{0}$ and $\left(\Delta C / C_{0}\right)$ is nonlinear, and the deviation of linearity is $\epsilon$

$\epsilon=\frac{U_{i}}{4} \frac{\left(\Delta C / C_{0}\right)^{2}}{2+\left(\Delta C / C_{0}\right)}$.

If we set $K$ as the ratio between $\epsilon$ and linearity, then

$K=\frac{\Delta C / C_{0}}{2+\left(\Delta C / C_{0}\right)}<\frac{\Delta C / C_{0}}{2}$.

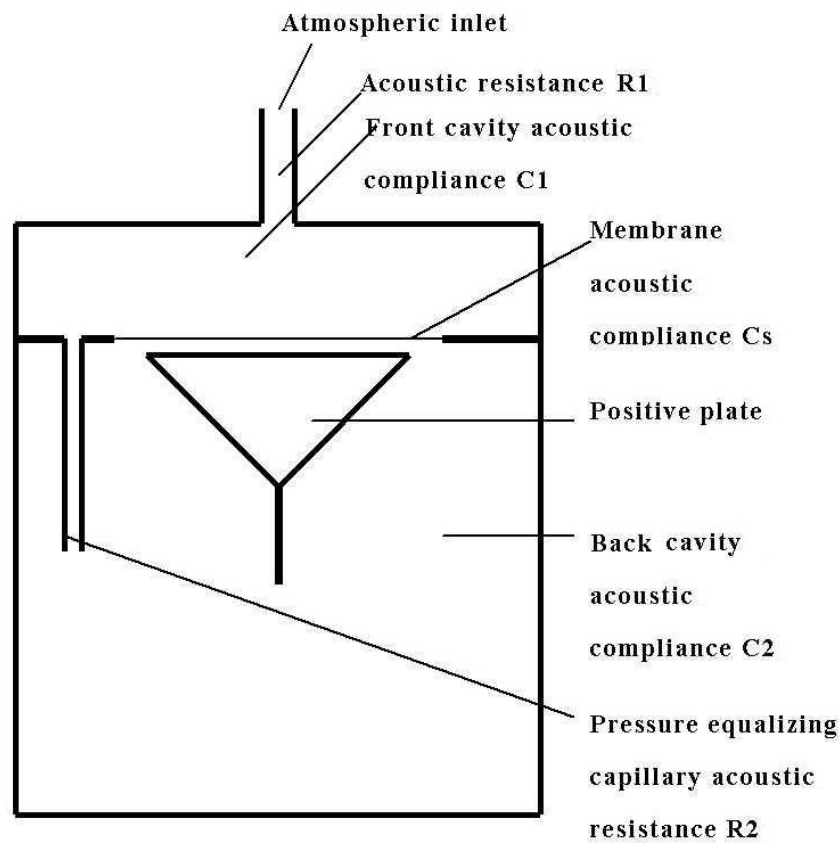

Fig. 8. Diagrammatic sketch of infrasonic condenser microphone.

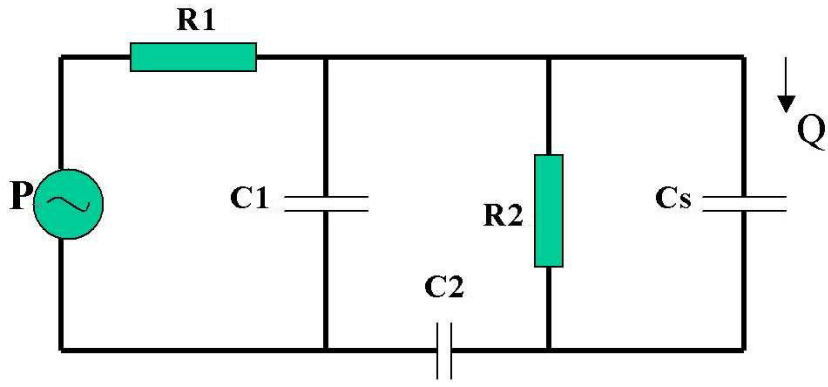

Fig. 9. Equivalent circuit for condenser microphone.

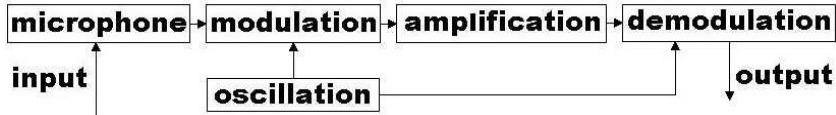

Fig. 10. Operation diagrams for condenser microphone.

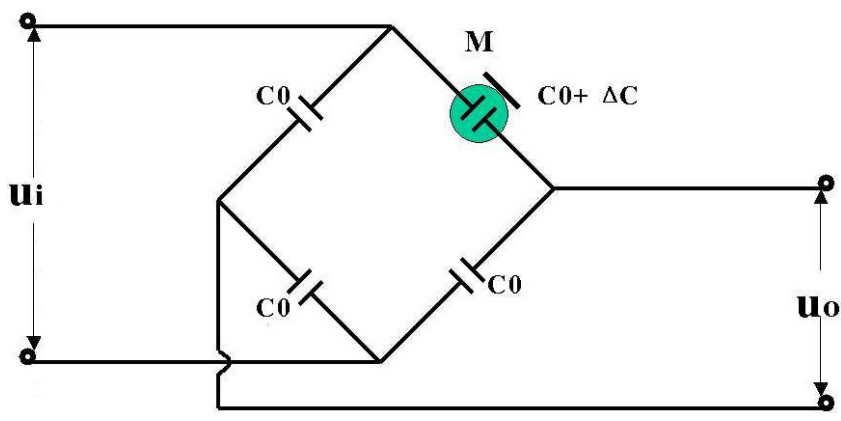

Fig. 11. Capacitance bridge modulation-amplitude principle. 


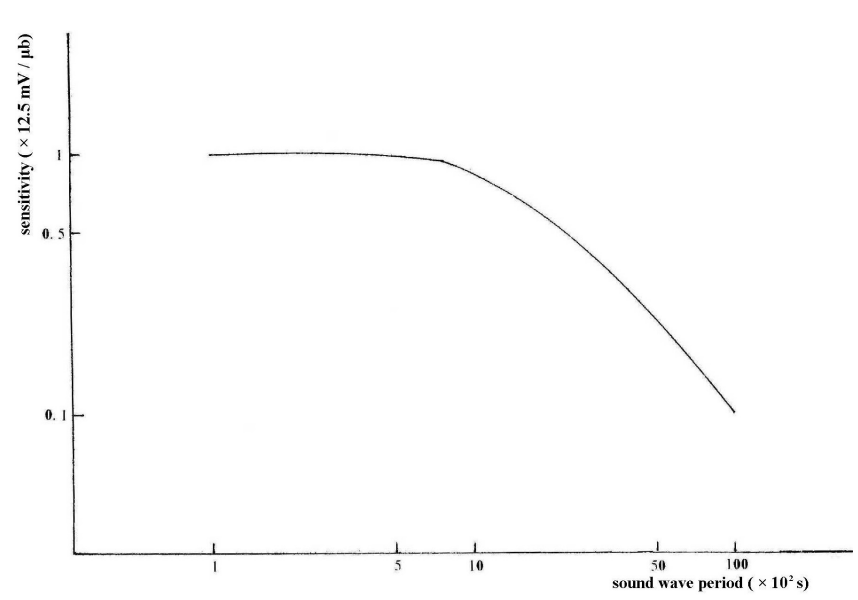

Fig. 12. Sound wave period dependence of sensitivity of the infrasonic wave sensor.

When $K \leq 1 \%$ is demanded, then $\Delta C / C_{0} \leq 2 \%$ should be satisfied.

If $R_{1}$ and $C_{1}$ are not considered, then the sensitivity of the transducer $S_{Q}$ can be represented by $Q$ according to the following equation

$S_{Q}=\frac{Q}{P}=\frac{\omega C_{2} C_{s} R_{2} e^{j \phi}}{\left[1+\omega^{2} R_{2}^{2}\left(C_{2}+C_{s}\right)^{2}\right]^{1 / 2}}$

in which the phase angle $\phi$ is given by the relation

$\phi=\frac{\operatorname{arctg} 1}{\omega R_{2}\left(C_{2}+C_{s}\right)}$.

In the case of high frequency, Eq. (4) can be simplified as

$S_{Q} \approx \frac{C_{2} C_{s}}{\left(C_{2}+C_{s}\right)}$

Here, the phase angle $\phi \approx 0$. The low frequency cutoff pe$\operatorname{riod} T_{N}$ is as follows

$T_{N}=2 \pi R_{2}\left(C_{2}+C_{S}\right)=2 \pi \tau$.

Here, $\tau=R_{2}\left(C_{2}+C_{s}\right)$ is a constant of time. From Eq. (6), we can see that the sensitivity is determined by the acoustic compliances of the back cavity and the membrane. When the volume of the back cavity is fixed, its compliance is unchanged. The decisive factor of the sensitivity is thereby the acoustic compliance of the circle membrane, which relates to its material, diameter, thickness and surface tension. The sensitivity $S_{c}$ can be described with the variable of changed capacitance as

$S_{c}=\frac{\Delta C / C_{0}}{P}=\frac{S_{Q}}{d A}$.

Here, $d$ represents the distance between membrane and positive plate; $A$ is the active area of the transducer capacitance (Xie et al., 2001).

The sensitivity of our apparatus is of $1000 \mathrm{mV}$ per $8 \mathrm{~Pa}$ sonic pressure. Figure 12 shows the sensitivity of the infrasonic wave sensor depending on the sound wave period.
Our experience (Li et al., 1997, 2002) indicates that, under usual conditions, our sound sensor is able to detect an abnormal signal of infrasonic waves before an earthquake with a magnitude over $M_{s} 7$ around the world. Generally, within 9 days after the end of an abnormal infrasonic sound wave signal, an earthquake would occur. The amplitude of the abnormal signal determines the magnitude of the earthquake. So, the abnormal signal can indicate the occurring time and the magnitude of the earthquakes. The difference in time between a forecast and the an event's occurence is no more than 4 days, and the magnitude error is less than $0.8\left(M_{S}\right)$. However, the epicenter cannot yet be forecasted. Our statistics of the earthquakes which occurred during the time period of 1989 to 1998 with a magnitude above $M_{s} 7$ around the world, demonstrated that more than $80 \%$ of them can be related to an abnormal infrasonic wave before their occurrence. However, there exists a lot of noise in the infrasonic wave observations is produced by atmospheric phenomena, such as strong wind and thunderstorms; therefore, we feel that further research is needed in order to increase the effectivity of the method.

From 24 March to 2 April 1997, abnormal infrasonic sound wave signals appeared continuously. The strongest signal reaching as high as $1.250 \mathrm{mV}$ (10 Pa sonic pressure) appeared from 10:00 to 13:20 on 1 April (see Fig. 13). Based on the ending time of the signal and its amplitude, we predicted that the earthquake would occur before 11 April, with a magnitude of 7.0-7.5.

\subsubsection{Abnormal jump frequency of budgerigars}

We kept a couple of budgerigars (a kind of parrot) in a cage equipped with an horizontal pole. We fixed a sensor connected with a counter to the pole (and connected it to a counter). The counter recorded the jump frequency of the birds automatically. An unusually large value of the jump frequency was considered as an anomaly. We found that there would be an earthquake in ten days after an abnormal state appeared (Li et al., 1989). We do not know why, but this method was found to be useful in predicting the time of the earthquake but not the magnitude or the location (Li et al., 2002). Strikingly, the method worked for distant earthquakes as well (Chen et al., 2001); abnormal signals appeared before strong earthquakes in Japan and Italy. It should be noticed that an abnormal state is not always followed by $E Q$. Other natural hazards and the oestrum of the bird should be considered. Our statistics of the earthquakes with magnitudes higher than $M_{s}$ 7, which occurred from 1995 to 2000 (with the magnitude above $M_{S} 7$ ) around the world, demonstrated that $81 \%$ of them can be related to an abnormal state of the budgerigars before their occurrence.

On 2 April 1997, the jump frequency of the birds appeared abnormal, reaching as high as 2173 jumps per day (600 to 700 jumps per day for normal state) (Fig. 14). Based on this, we predicted that the time of the earthquake occurrence would be before 11 April. 


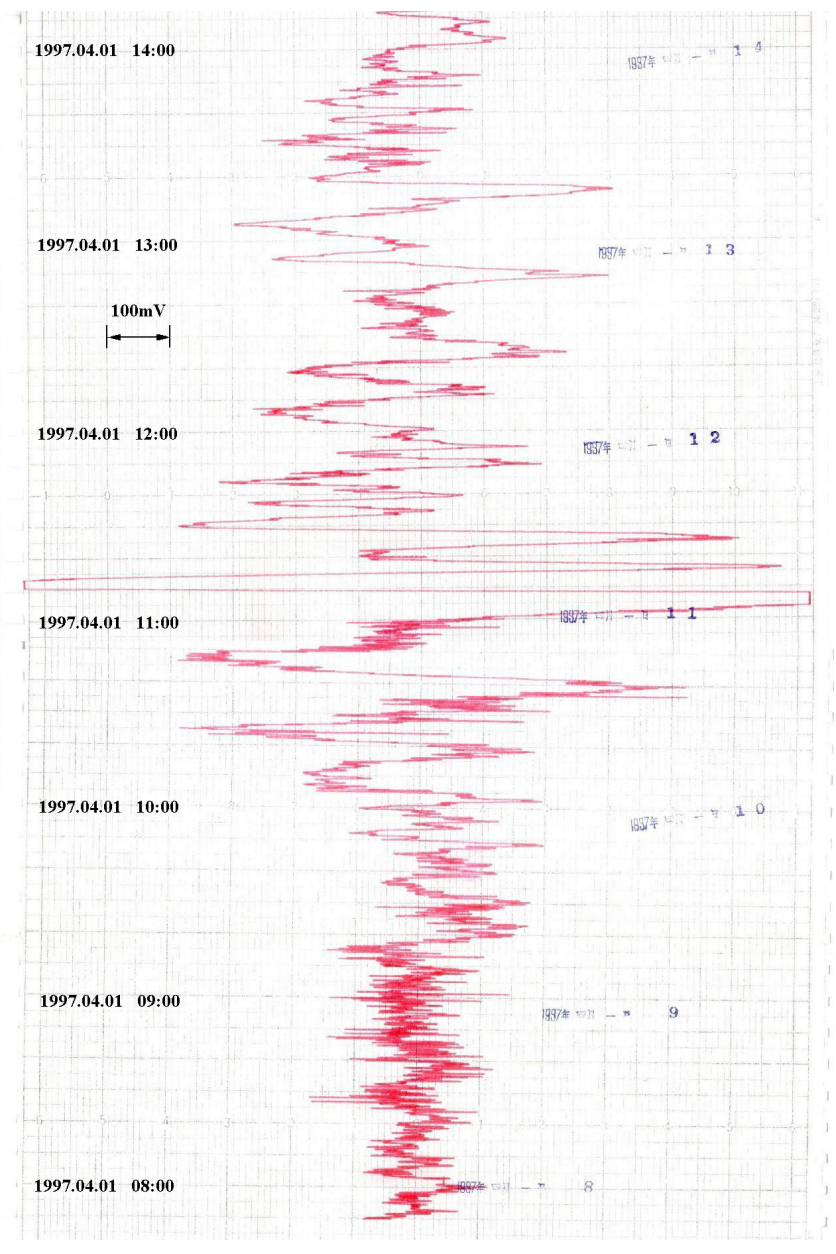

Fig. 13. Abnormal curve of infrasonic wave during 8:00 to $14: 00$ on 01 April 997.

\subsubsection{Superposition of tide generating force resonance}

A further indication was provided by the superposition of tide generating force resonance (Ren et al., 1997; Li et al., 1998; Ren, 1998, 2002) (which will be reported in detail in a future article for NHESS by Ren).

\subsection{5 (Summary) The imminent earthquake prediction}

Based on the time of tide-generating force resonance, the abnormal infrasonic sound waves, the abrupt change in the crustal stress and the abnormal jumping of the birds, we decided that the time of the earthquake would be on 7 April \pm 3 days, that is during 4 to 10 April.

Based on the sonic pressure of the infrasonic sound waves, and the abnormal amplitude of the crustal stress change, we predicted that the magnitude of the earthquake would be $M_{s} 7.0-7.5$.

Based on the area of common superposition of tidegenerating force resonance, the similarities of the change in crustal stress with that of past earthquakes, the location of the epicenter was gauged to be within the area $38.7^{\circ}-40.2^{\circ} \mathrm{N}$, $75^{\circ}-77^{\circ} \mathrm{E}$.

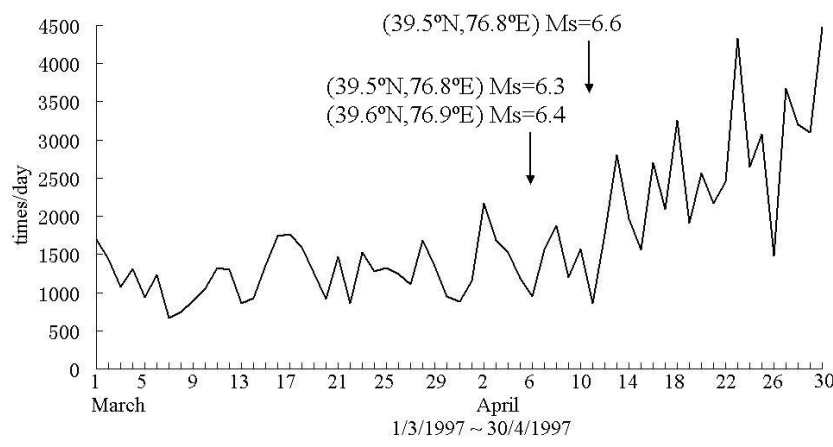

Fig. 14. Jumping frequency of budgerigars during 01 March 1997 to 30 April 1997 (the value for every day).

Thus, the imminent prediction in Jiashi, Xinjiang was made by adopting the multiple monitoring methods on different subjects.

\section{Other experiments of imminent earthquake prediction}

Using the same multiple methods as described in this paper, we have made experiments of imminent earthquake prediction since May 1995. Among them, there are 4 comparatively successful experiments besides the Xinjiang earthquake. Namely, we predicted the $M_{S} 6.4$ earthquake in Baotou, Inner Mongolia Autonomous Region, China in 1996 (Table 2) (Li et al., 1998), the $M_{s} 6.4$ earthquake in the northern Izu Island Region, Japan in 2000 (Table 3) (Li et al., 2002) and the $M_{s} 7.5$ earthquake, east of Taiwan in 2001 (Table 4) (Wang, 2002). Additionally, there have been three mid-term predictions (Table 5, 6 and 7) (Bai, Z. Q. and Li, J. Z., 2001; Li et al., 2003).

The accuracy of our predictions to strong earthquakes over $M_{s} 6$ meets the following standard: the occurring time within 9 days, the magnitude error less than 0.8 and the range of epicenter in the square area of 2 degrees (both for the longitude and the latitude). Moreover, although we have not yet published this, we have recorded distinct imminent precursors for other strong earthquakes that occurred in recent years, including the $M_{s} 7.2$ earthquake in Kobe, Japan on 17 January 1995 , the $M_{s} 7.8$ earthquake in Turkey on $17 \mathrm{Au}-$ gust 1999, the $M_{s} 7.7$ earthquake in Taiwan on 21 September 1999, the $M_{s} 7.6$ earthquake in Central America on 13 January 2001, the $M_{s} 7.9$ earthquake in India on 26 January 2001, the $M_{s} 8.1$ earthquake in Qinghai province, China on 14 November 2001, and the $M_{S} 6.8$ earthquake in Xinjiang, China on 24 February 2003. 
Table 2. Verification of the imminent earthquake prediction of the earthquake that occurred in Baotou, Inner Mongolia Autonomous Region, China, May 1996

\begin{tabular}{|c|c|c|c|}
\hline & Prediction & Actual & Error \\
\hline Time & $18 \sim 25$ March 1996 & 3 May 1996 & 39 days \\
\hline Magnitude & $M_{s}=6.5$ & $M_{S}=6.4$ & 0.1 \\
\hline Place & $\begin{array}{ll} & 40.5^{\circ} \sim 42^{\circ} \mathrm{N} \\
\text { China } & 108^{\circ} \sim 110^{\circ} \mathrm{E}\end{array}$ & $\begin{array}{ll} & 40.8^{\circ} \mathrm{N} \\
\text { China } & \\
& 109.6^{\circ} \mathrm{E}\end{array}$ & No error \\
\hline
\end{tabular}

Table 3. Verification of the imminent earthquake prediction of the group of strong earthquakes that occurred in the northern Izu Island Region, Japan, July 2000

\begin{tabular}{|c|c|c|c|}
\hline & Prediction & Actual & Error \\
\hline Time & 1 - 9 July 2000 & $\begin{array}{l}1 \text { July } 2000 \\
9 \text { July } 2000 \\
9 \text { July } 2000\end{array}$ & $\begin{array}{l}\text { No error } \\
\text { No error }\end{array}$ \\
\hline Magnitude & $M_{s}=7.0 \pm 0.5$ & $\begin{array}{c}M_{S}=6.4 \\
M_{S}=6.0 \\
\text { Miyakejima Island Volcano erupted }\end{array}$ & 0.1 \\
\hline Place & $\begin{array}{c}33.5^{\circ}-35.5^{\circ} \mathrm{N} \\
138.5^{\circ}-140.5^{\circ} \mathrm{E}\end{array}$ & $\begin{array}{l}35.1^{\circ} \mathrm{N}, 138.7^{\circ} \mathrm{E} \\
34.9^{\circ} \mathrm{N}, 139.0^{\circ} \mathrm{E} \\
34.1^{\circ} \mathrm{N}, 139.5^{\circ} \mathrm{E}\end{array}$ & No error \\
\hline
\end{tabular}

Table 4. Verification of the imminent earthquake prediction of the earthquake that occurred east of Taiwan, December 2001

\begin{tabular}{|c|c|c|c|c|c|}
\hline & \multicolumn{2}{|c|}{ Prediction } & \multicolumn{2}{|c|}{ Actual } & Error \\
\hline Time & \multicolumn{2}{|c|}{ 10-18 December 2001} & \multicolumn{2}{|c|}{18 December 2001} & No error \\
\hline Magnitude & \multicolumn{2}{|c|}{$M_{S}=7.0 \pm 0.5$} & \multicolumn{2}{|c|}{$M_{s}=7.5$} & No error \\
\hline \multirow{2}{*}{ Place } & East to & $25^{\circ} \pm 1^{\circ} \mathrm{N}$ & East to & $23.9^{\circ} \mathrm{N}$ & $0.1^{\circ}$ \\
\hline & Taiwan & $123.2^{\circ} \pm 1^{\circ} \mathrm{E}$ & Taiwan & $123^{\circ} \mathrm{E}$ & $0^{\circ}$ \\
\hline
\end{tabular}


Table 5. Verification of the mid-term earthquake prediction of the earthquake that occurred in Yunnan Province, China, February 1996 (issued on 15 January 1996)

\begin{tabular}{|c|c|c|c|}
\hline & Prediction & Actual & Error \\
\hline Time & 15 January 1996 - 31 December 1996 & 3 February 1996 & No error \\
\hline Magnitude & $M_{s}=7.0 \pm 0.5$ & $M_{s}=7.0$ & No error \\
\hline Place & $\begin{array}{c}25^{\circ}-28^{\circ} \mathrm{N} \\
100^{\circ}-103^{\circ} \mathrm{E}\end{array}$ & $\begin{array}{ll} & 27.2^{\circ} \mathrm{N} \\
\text { China } & \\
& 101.1^{\circ} \mathrm{E}\end{array}$ & No error \\
\hline
\end{tabular}

Table 6. Verification of the mid-term earthquake prediction of the earthquake that occurred east of Taiwan, March 2002 (issued on 10 February 2002)

\begin{tabular}{|c|c|c|c|c|c|}
\hline & & diction & \multicolumn{2}{|c|}{ Actual } & Error \\
\hline Time & \multicolumn{2}{|c|}{10 February $2002-10$ February 2003} & \multicolumn{2}{|c|}{31 March 2002} & No error \\
\hline Magnitude & \multicolumn{2}{|c|}{$M_{s}=7.0 \pm 0.5$} & \multicolumn{2}{|c|}{$M_{s}=7.5$} & No error \\
\hline \multirow{3}{*}{ Place } & East to & $25^{\circ} \pm 2^{\circ} \mathrm{N}$ & East to & $24.4^{\circ} \mathrm{N}$ & \multirow{3}{*}{ No error } \\
\hline & & & & & \\
\hline & Taiwan & $122^{\circ} \pm 2^{\circ} \mathrm{E}$ & Taiwan & $122.1^{\circ} \mathrm{E}$ & \\
\hline
\end{tabular}

Table 7. Verification of the mid-term earthquake prediction of the earthquake that occurred in Wuqia, Xinjiang Automous Region, China, December 2002 (issued on 10 February 2002)

\begin{tabular}{|c|c|c|c|}
\hline & Prediction & Actual & Error \\
\hline Time & 10 February $2002-10$ February 2003 & 25 December 2002 & No error \\
\hline Magnitude & $M_{s}=6.5 \pm 0.5$ & $M_{s}=5.7$ & 0.3 \\
\hline Place & $\begin{array}{l}39.7^{\circ} \pm 2^{\circ} \mathrm{N} \\
75.6^{\circ} \pm 2^{\circ} \mathrm{E}\end{array}$ & $\begin{array}{ll} & 39.6^{\circ} \mathrm{N} \\
\text { China } & \\
& 75.4^{\circ} \mathrm{E}\end{array}$ & No error \\
\hline
\end{tabular}




\section{Conclusion}

According to the standard of the UN Global Program (ESTAPE, The Evaluation of Short-Term and Annual Prediction of Earthquakes) (Chu and Col, 1999), more than $40 \%$ of a total of 20 imminent predictions issued by us since 1995 , could be qualified as having more than 60 points (100 points for full qualification). If the two items, i.e. the occurring time and the magnitude are predicted accurately, the prediction can be qualified as having 60 points. In our opinion, epicentral location is more difficult to determine than the occurring time and magnitude. We could draw a conclusion that strong earthquakes could be predicted, and some of them have actually been predicted on the basis of our methods. (However, it is possible that there exists an anomaly, yet no actual event followed.) Yet there exist anomalies which are not correlated with earthquake events and the physical mechanisms responsible for generating the pre-seismic signals we observe are unknown. The appearances of such signals as crustal stress anomaly and jumping anomaly of birds before earthquakes in sites located many thousand of kilometers away from the shock epicenter, and the triggering effect of the tide-generating force resonance, are all extremely difficult to be explained by the known theories. More research is certainly needed to clarify the mechanisms, as well as to accumulate the case studies and to develop the accuracy of prediction. Our attitude towards the earthquake prediction is optimistic.

Acknowledgements. We would like to express our sincere thanks to Prof. S. Uyeda, Earthquake Prediction Research Center at Tokai University, Japan and Prof. M. E. Contadakis, Aristotle University of Thessaloniki, Greece for valuable suggestions and kindly help.

\section{References}

Bai, Z. Q. and Li, J. Z.: Elementary Experiments on Prediction of Earthquakes in West of China with Multi-subjects and Multimethods, Sci. Tech. Press, Yunnan China, (in Chinese), Annual Chinese Geophys. Soc., 225, 2001.

Chen, W. S., Bai, Z. Q., and Zhu, X.: Study on the law of abnormal behavior of budgerigars to the long-distance earthquake, Sci. Tech. Press, Yunnan China, (in Chinese), Annual Chinese Geophys. Soc., 226, 2001.

Chu, J. and Col, J-M: Evaluation for short-term and annual prediction of earthquakes, in: Atmospheric and Ionospheric Electromagnetic Phenomena Associated with Earthquakes, edited by Hayakawa, M., Terra Scientific Publishing Company (TERRAPUB), Tokyo Japan, 919-929, 1999.

Geller, R. J., Jackson, D. D., Kagan, Y. Y., and Mulargia, F.: Earthquake cannot be predicted, Science, 275, 1616-1617, 1997.

Li, J. Z., Cao, M., Xia, Y. Q., and Mao, P. S.: An experimental study on rock compressing and emission of electromagnetic waves be- fore earthquake, (in Chinese), J. Beijing Polytechnic University, 8, 47-53, 1982.

Li, J. Z.:Abnormal behavior of selected animals prior of earthquake, (in Chinese), J. Beijing Polytechnic University, 15, 73-75, 1989.

Li, J. Z., Shen, Z., and Xia, Y. Q.: Imminent-term earthquake prediction, (in Chinese), J. Beijing Polytechnic University, 16, 9-16, 1990.

Li, J. Z., Lu, S. L., Huang, X. N., Xia, Y. Q., and Chen, W. S.: Reducing seismic hazard and the measurement of crustal stress, Fifth U.S. National Conference on Earthquake Engineering Proceedings, III, 387-396, 1994.

Li, J. Z., Xia, Y. Q., Chen, W. S.: The precursory information of impending earthquake learnt from the strong earthquakes of the past few years in Japan, (in Chinese), J. Beijing Polytechnic University, 21, 1-12, 1995.

Li, J. Z., Liu, Y. R., Chen, W. S., Xia, Y. Q., Lu, S. L., and Chu, J.: Infrasonic wave method for the imminent earthquake prediction, (in Chinese), in: Geophysics and China Construction, Geological Publishing House, Beijing China, 295-296, 1997.

Li, J. Z., Ren, Z. Q., and Huang, X. N.: The imminent prediction of the strong earthquake group in Jiashi, Xinjiang, (in Chinese), in: Study on Reducing Natural Disasters in China, Publishing House of Science and Technology, Beijing, China, 409-413, 1998,

Li, J. Z., Bai, Z. Q., Xia, Y. Q., Chen, W. S., Liu, Y. R., and Huang. J.: Methods to monitor imminent precursors for earthquakes, in: Seismo Electromagnetics: Lithosphere-AtmosphereIonosphere Coupling, edited by Hayakawa, M. and Molchanov, O. A., Terra Scientific Publishing Company (TERRAPUB), Tokyo Japan, 443-448, 2002.

Li, J. Z., Chen, W. S., Bai, Z. Q., and Xia, Y. Q.: Possibility to solve the worldwide scientific problem of eartquake prediction in China, (in Chinese), Earth Science Frontiers, 10, 89-91, 2003.

McDonald, J. A.: The structure of atmospheric turbulence and its application to the design of pope arrays, Geophys, J. R. Astr. Soc, 26, 99-109, 1971.

Ren, Z. Q., Li, J. Z., and Huang, X. N.: Important advances in imminent earthquake prediction test, (in Chinese), in: Geophysics and China Construction, Geological Publishing House, Beijing, China, 292-294, 1997.

Ren, Z. Q.: Study on trigger mechanism of tide-generating force resonance to strong earthquakes, (in Chinese), in: Study on Reducing Natural Disasters in China, Publishing House of Science and Technology, Beijing China, 400-404, 1998.

Ren, Z. Q.: Triggering mechanism of tide generating force resonance on impending violent earthquakes and prediction verification, in: Seismo Electromagnetics: Lithosphere-AtmosphereIonosphere Coupling, edited by Hayakawa, M. and Molchanov, O. A., Terra Scientific Publishing Company (TERRAPUB), Tokyo Japan, 455-461, 2002.

Wang, R., Ding, Z. Y., and Yin, Y. Q.: Fundamental of solid mechanics, (in Chinese), Geological Publishing House, Beijing, China, 192-198, 1979.

Wang, W. L.: The report of the workshop on prediction of natural hazard in China, (in Chinese), J. Reduction of Natural Hazard in China, 2, 57, 2002.

Xie, J. L., Tao, Z. D., and Xie, Z. H.: A condenser microphone with IMS, in: Proceedings of CTBT Infrasound Technology Workshop, Hawaii, USA, Nov. 12-15, 2001. 